\title{
Health Economy Reporting: A Case Review from Germany
}

\author{
Prof Dr Klaus-Dirk Henke \\ Faculty VII Economics and Management \\ Institute of Economics and Law \\ Technical University of Berlin, Germany \\ Benno Legler \\ WifOR, Head of Health Economy Research \\ Berlin, Germany \\ Dr Mirko Claus \\ Resident Physician \\ School of Hygiene, Preventive medicine and Public Health \\ University of Padova, Italy \\ Prof. Dr Dennis A. Ostwald \\ Faculty for Economics and Management in SIBE at SHB \\ Berlin \&WifOR, Founder and CEO \\ Darmstadt, Germany
}

\begin{abstract}
Governments all over the world need to target investments in health to generate jobs and promote inclusive and sustainable economic growth as they implement the 2030 Agenda for Sustainable Development. This report reviews a well-established methodology of health economy reporting that quantifies and analyses the health sector's economic impact on growth and employment based on national accounts. The report concludes that the methodology enables evidence-based health policy to steer and guide investments for health, employment and inclusive and sustainable growth. Value- and evidence-based public health investment provides effective and efficient, inclusive and innovative solutions that can drive social, economic and environmental sustainability. Investing for health and well-being is a driver and enabler of sustainable development and empowers people to achieve the highest attainable standard of health for all.
\end{abstract}

\section{Introduction}

Health directly contributes to increased productivity, a more efficient workforce, healthier ageing, less expenditure on sickness and social benefits, and less tax revenue lost(World Health Organization 2013).In addition, as one of the world's largest and most rapidly growing industrial and service sectors, the health sector is a strong pillar for employment in most high-income countries. Encompassing a wide range of business sectors, services, manufacturers and suppliers, the health sector is a major employer, landowner, builder and consumer, driver of research and innovation and a significant sector in the international competition for people, ideas and products.

The 2030 Agenda for Sustainable Development (United Nations General Assembly 2015)with its' 17 Sustainable Development Goals (SDGs) and 169 targets requires integrated approaches, deep interconnections and cross-cutting elements to leave no one behind. SDG 3, ensuring good health and well-being for all at all ages, is interwoven throughout the 2030 Agenda with its targets linking directly to other goals such as poverty (SDG 1), nutrition (SDG 2), education (SDG 4), gender equality (SDG 5), water and sanitation (SDG 6), infrastructure, industrialisation and innovation (SDG 9), inequality (SDG 10), cities and communities (SDG 11), production and consumption (SDG 12), climate action (SDG 13) and peace, justice and institutions (SDG 16)(United Nations High Level Political Forum on Sustainable Development 2017). They all represent determinants of health and impact on health equity. Progress in health critically depends on progress in other sectors and health in all policies requires health in all SDGs. On the other hand, sustainable health systems and hhealthcare critical for achieving the SDGs, and the health sector can play an important role by walking-the-talk through its own investments and sustainable(United Nations Informal Interagency Task Team on Sustainable Procurement in the Health Sector (SPHS) n.d.; World Health Organization 2015). 
The High-Level Commission on Health Employment and Economic Growth demonstrated how targeted investments in health play a key role as job generator and driver of inclusive and sustainable economic growth, focusing on health workforce investment(World Health Organization 2016). Building on but going beyond the health workforce investments, health economy reporting provides a structured approach for governments, private sector and general public stakeholders to better understand the size and impact of the health economy as a starting point for planning and evaluating its strategic role for health and sustainable and inclusive economic growth.

Given the increasing interest in this approach, this report reviews a well-established methodology of health economy reporting that quantifies and analyses the health sector's economic impact on growth and employment based on national accounts, collaboratively developed between Ministries of Health and Ministries of Economics. The methodology reviewed here is a distinct concept to that of national health accounts (NHA), which aim to support health system governance and decision-making by estimating the amount and characteristics of health spending. Health economy reporting using national accounts goes a step further bycomprehensively informing health investment decisions about their employment and growth impacts. This review focuses on the example from Germany, where health economy reporting based on national accounts is a well-established methodology and broadly applied. The method is well applicable to other countries around the world.

By dividing the health economy into various segments, the reporting system comprehensively represents the health economy as a heterogenous inter-sectoral industry, which produces goods and provides services(Federal Ministry of Economics and Technology (BMWi) 2012; Henke et al. 2010).It also shows its' structures and interrelations with the population, providers, insurers, and government. The reporting system also offers a base for economic impact analysis of the health economy as a whole, as well as for its various segments(Henke and Ostwald 2012). Moving towards an investment segments approach to health (Hamelmann et al. 2017), the reporting system analyses a whole array of issues, including the direct, indirect and induced total contributions and related multiplier values for gross value added (GVA), employment and foreign trade of the overall health economy, as well as for selected of the health economy, depending on existing and methodologically feasible categorizations and disaggregations of a country's health economy. In addition, the methodology allows for establishing time series to analyze trends and new developments related to the contribution of health economies to growth and trade, as well as the supply and demand of the health economy workforce ${ }^{1}$ (Schwärzler and Kronenberg 2016).

This analytic summary report serves as an entry point for countries who want to use expert services available for health economy reporting and related capacity building as a practical approach towards the development and implementation of a systematic strategy to optimize the impact of health sector investments on sustainable and inclusive economic growth. Chapter 2 outlines the frameworks, concepts and methodological background of health economy reporting. Chapter 3 demonstrates the variety of uses and analytical capacities the methodology offers. Chapter 4 summarises the aspects the methodology can quantify and analyse. Chapter 5 gives an outlook on applying health economy reporting.

\section{Frameworks, Concepts and Methods}

Comprising the production and marketing of products and services, which serve to prevent disease, promote and restore health, the health economy is a key economic sector, a job generator and a driver of inclusive economic growth (World Health Organization 2016).The frameworks, concepts and methods underlying the German health economy reporting were developed within projects on behalf of the Federal Ministry for Economic Affairs and Energy of Germany (BMWi) (2015).

\subsection{The health economy in the 4-quadrant-model}

Health economy reporting follows a product- and service-, rather than sector-specific segmentation, which separates the overall health economy into a core and an extended area, using a total of twelve aggregate categories of products and services, as shown in Figure 1.

\footnotetext{
${ }^{1}$ It should be noted that the aspects mentioned here can be analyzed using data from national accounts and health expenditure surveys only. Complementing those datasets with health financing and distribution, cost-of-illness and health labour accounts enables more detailed analyses of the financing, productivity and health dividends of health economies. Since these analyses are done routinely using a range of existing methods and tools, this analytical review focuses solely on the methods to calculate the GVA, employment and foreign trade impacts of health economies.
} 
Figure 1 Core and extended area of health economy

\begin{tabular}{|lll|}
\hline & Medication & \\
\hline
\end{tabular}

Source: Adapted fromFederal Ministry for Economic Affairs and Energy (BMWi) 2017a.

The core area, quantifies products and services captured by health expenditure surveys. The extended area, quantifies products and services not captured in health expenditure surveys although they promote health. The categorical definition of the health economy excludes products and services classified as medical that do not promote and preserve health, such as plastic surgery or veterinary pharmaceutical products ${ }^{2}$ (Schwärzler and Kronenberg 2016).

Further to the product- and service-specific segmentation, the German health economy reporting methodology distinguishes the primary and secondary health markets based on financing. The primary health market includes products and services funded by private or statutory health insurance, or through tax revenue based public expenditures. The secondary health market includes products and services funded through personal consumption expenditures (Schwärzler and Kronenberg 2016).

This segmentation of the health economy by products and financing yields a 4-quadrant-model (Figure 2), which allows analyzing dynamics and interrelationships within the health economy.

\section{Figure 1The health economy in the 4-quadrant model}

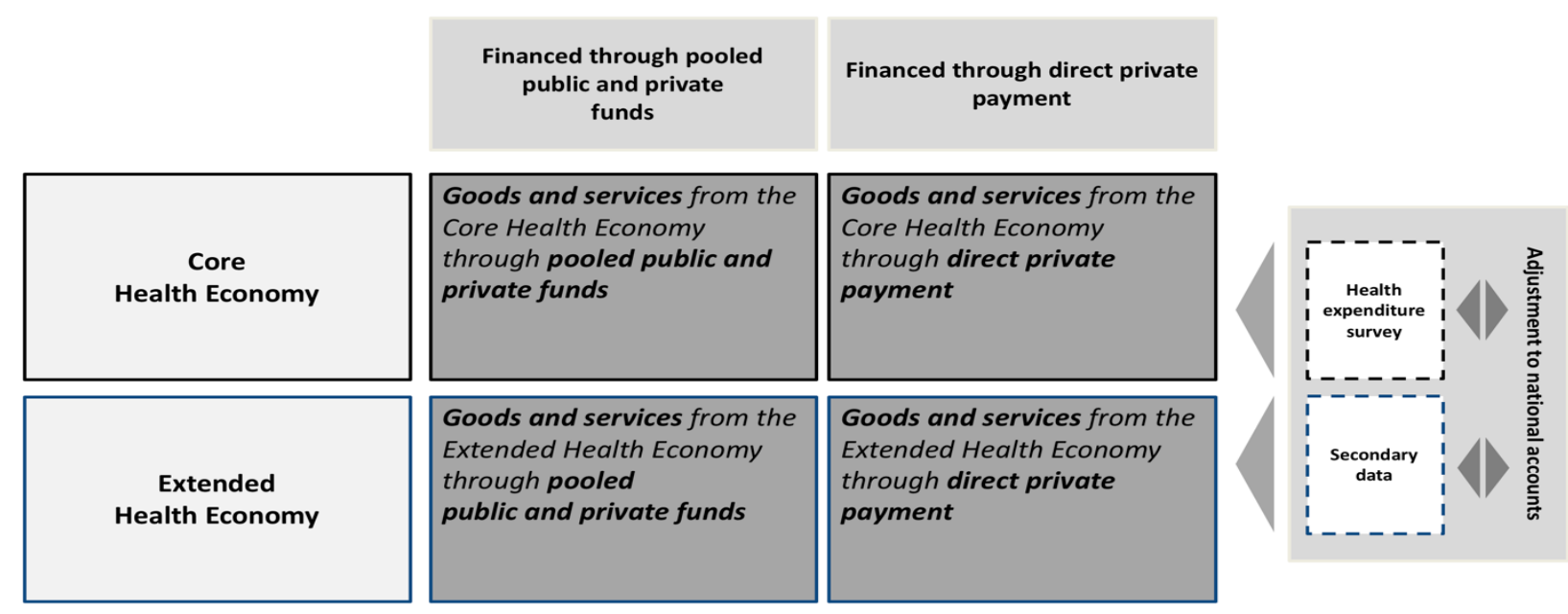

Source: Adapted from Henke et al. 2010.

${ }^{2}$ For details on the segmentation of products and services, see Annex 1. 


\subsection{The economic footprint of the health economy: direct, indirect and induced effects}

The economic footprint (Figure 3) in the context of the health economy reporting summarizes key economic indicators, considering direct, indirect and induced spill-over effects, e.g. GVA, employment and foreign trade. The economic footprint also includes multipliers to quantify the relationship with direct, indirect and induced effects(Schneider et al. 2015).

Direct effects originate from production within the health economy itself, while indirect effects are generated through investments and auxiliary production of intermediary inputs of other sectors, such as energy, cleaning services, equipment and construction, chemicals for the production of medicine, and induced effects stem from spending of generated income and revenue (Schneider et al. 2015).

\section{Figure 3The economic footprint of the health economy}

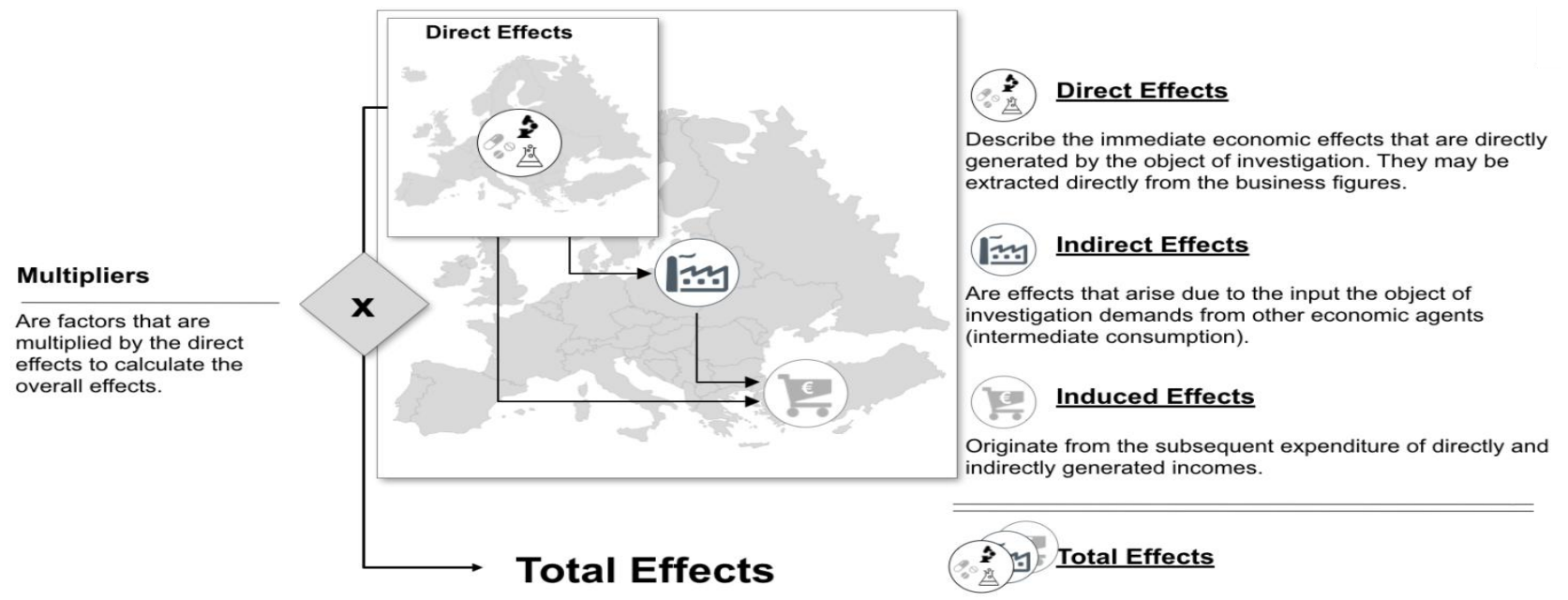

Are the sum of direct, indirect and induced effects and represent the Economic Footprint.

Source: Adapted from Schwärzler and Legler 2017.

\subsection{Data bases and international statistical standards}

Compiling national health economy reports requires two datasets, both of which are based on international statistical standards and are usually provided annually by national statistical offices.

On the one hand, national accounts provide the macroeconomic statistical framework, wherein satellite accounts serve to describe, analyze and quantify aspects of interest, such as trends and patterns of consumption, investment or intermediary use. The compilation of national accounts is based on the System of National Accounts (SNA)(European Commission et al. 2009).

On the other hand, health expenditure surveys focus on consumption, provision and financing patterns of health products and services. They consider all products and services, which primarily aim to promote and preserve health or prevent illness and are compiled based on the System of Health Accounts (SHA)(Organisation for Economic Cooperation and Development, World Health Organization, and Statistical Office of the European Communities 2011)- an international guideline for the definition and accounting mechanisms of health expenditure. In matching data from national accounts with health expenditure surveys ${ }^{3}$, health economy reports account for health-related products and services and their producing entities and service providers within the overall economy without disrupting balancing conditions and concepts of national accounts.

\subsection{Developing health economy reports}

\section{Compiling health-specific supply and use tables}

To account for health-related products and respective producing entities within the overall economy while maintaining balancing conditions and concepts of national accounts, data from national accounts need to be matched with the health expenditure survey. To do this, first, products and sectors are disaggregated into the core and extended health area, as well as a non-health area, which is excluded from the analysis. Second, tables are aggregated to reconcile with official aggregated data. Third, the twelve health-specific categories are defined and aggregation is applied on the product side of the disaggregated health-specific tables to obtain tangible classifications.

\footnotetext{
${ }^{3}$ Refer to Figure 2 to see how the data sets are matched.
} 
Then, input structures are adjusted between the core and extended health area and the non-health area. Last, data are aggregated sector-wise in accordance to the previously defined product side classifications. This results in square supply and use tables, consisting of 14 core and 18 extended health related product and sector categories as well as 64 non-health categories. In order to match the health expenditure survey with the final consumption patterns of the use table, the health-specific supply and use tables are then compiled at purchasers' prices to allow straight-forward calculations (8).

\section{Calculating key indicators using input-output analyses}

First, an input-output table has to be calculated from just derived health-specific supply and use tables. In order to calculate the direct, indirect and induced $\mathrm{GVA}^{4}$ and employment, as well as, foreign trade impacts ${ }^{5}$ of health economies as key performance indicators, input-output-analyses are used. The multiplier values can then be calculated from the total values for each indicator. This can be done for the overall health economy, as well as for selected categories or segments depending on the specific area of interest, as well as the possibility for disaggregation at country level (Schwärzler and Kronenberg 2016).

\section{Examples}

While the following excerpts from various German health economy reports demonstrate the variety of uses and analytical capacities of health economy reporting, the selection does not capture the full breadth and depth of analytical possibilities, which would be beyond the scope of this review.

\subsection{National health economy reports}

\section{GVA, employment and trade impacts}

Health economy reports typically analyze basic health economy indicators (i.e. GVA, employment and foreign trade) for the overall health economy in absolute and relative numbers as a snapshot for individual reporting years, as well as, annual growth rates. In addition to these parameters, the reports may zoom into various segments and markets in more detail depending on the specific areas of interest. For example, the latest German health economy report focused on inpatient and outpatient services, the industrial health economy and pharmacies(Federal Ministry for Economic Affairs and Energy (BMWi) 2017a).

Table 1 GVA, employment and export effects of the German health economy, 2016

\begin{tabular}{|c|c|c|c|c|c|c|c|c|c|}
\hline & \multicolumn{3}{|l|}{ GVA } & \multicolumn{3}{|c|}{ Employment } & \multicolumn{3}{|l|}{ Exports } \\
\hline & Absolute & $\begin{array}{l}\text { Relative } \\
*\end{array}$ & Growth** & Absolute & Relative* & Growth** & Absolute & Relative* & Growth** \\
\hline $\begin{array}{l}\text { Total health } \\
\text { economy }\end{array}$ & 336.4 bn $€$ & $12 \%$ & $\begin{array}{l}+\quad 3.8 \% \\
\text { p.a. }\end{array}$ & $7 \mathrm{~m}$ & $16.1 \%$ & $\begin{array}{l}+\quad 1.6 \% \\
\text { p.a. }\end{array}$ & $116.1 \mathrm{bn} €$ & $8.2 \%$ & $\begin{array}{l}+\quad 7.4 \% \\
\text { p.a. }\end{array}$ \\
\hline $\begin{array}{l}\text { Inpatient } \\
\text { services }\end{array}$ & 94.1 bn $€$ & $28 \%$ & $\begin{array}{l}+\quad 3.8 \% \\
\text { p.a. }\end{array}$ & $2 \mathrm{~m}$ & $28 \%$ & $\begin{array}{l}+ \\
\text { p.a. }\end{array}$ & n.a. & n.a. & n.a. \\
\hline $\begin{array}{l}\text { Outpatient } \\
\text { services }\end{array}$ & 88.1 bn $€$ & $26.2 \%$ & $\begin{array}{l}+\quad 4.3 \% \\
\text { p.a. }\end{array}$ & $2.4 \mathrm{~m}$ & $34.4 \%$ & $\begin{array}{l}+\quad 1.8 \% \\
\text { p.a. }\end{array}$ & n.a. & n.a. & n.a. \\
\hline $\begin{array}{l}\text { Industrial } \\
\text { health } \\
\text { economy }\end{array}$ & 71.7 bn $€$ & $21.3 \%$ & $\begin{array}{l}+ \\
\text { p.a. }\end{array}$ & $0.9 \mathrm{~m}$ & $13.2 \%$ & $\begin{array}{l}+ \\
\text { p.a. }\end{array}$ & 106.9 bn $€$ & $92.1 \%$ & $\begin{array}{l}+\quad 7.4 \% \\
\text { p.a. }\end{array}$ \\
\hline Pharmacies & 5.1 bn $€$ & n.a. & $\begin{array}{l}+ \\
\text { p.a. }\end{array}$ & 163,200 & n.a. & $+1.1 \%$ & n.a. & n.a. & n.a. \\
\hline
\end{tabular}

* The percentages express the relative contribution towards the total economy in the case of the total health economy, and towards the total health economy in the case of selected segments and markets.

** The values reflect average annual growth rates between 2005 and 2016 based on the latest health economy report. Source: All data in this table are extracted from Federal Ministry for Economic Affairs and Energy (BMWi) 2017 a. Indirect and induced growth and employment impacts

${ }^{4} \mathrm{GVA}$ includes the compensation of employees, net taxes on production, consumption of fixed capital and net operating surplus. Imports and supplies are subtracted.

${ }^{5}$ It should be noted that while it is possible to calculate the contribution of health economies on foreign trade, the focus of this review and recommendation focuses first and foremost on the GVA and employment effects. 
Beyond its direct economic impact, the health economy as a cross-sectoral industry has spillover effects on other sectors. Indirect effects arise from intermediate consumption through the supply of inputs from other sectors to the health economy. Figure 4 demonstrates the reciprocal relationships of the German health economy with various other sectors, in particular the manufacturing sector, and to a lesser extent with corporate services, and trade, transportation and hospitality. Induced effects originate from the subsequent expenditure of directly and indirectly generated compensation of employees (Schwärzler and Kronenberg 2016).

Figure 4Proportional input $(\%)$ of industries to the German health economy, 2016

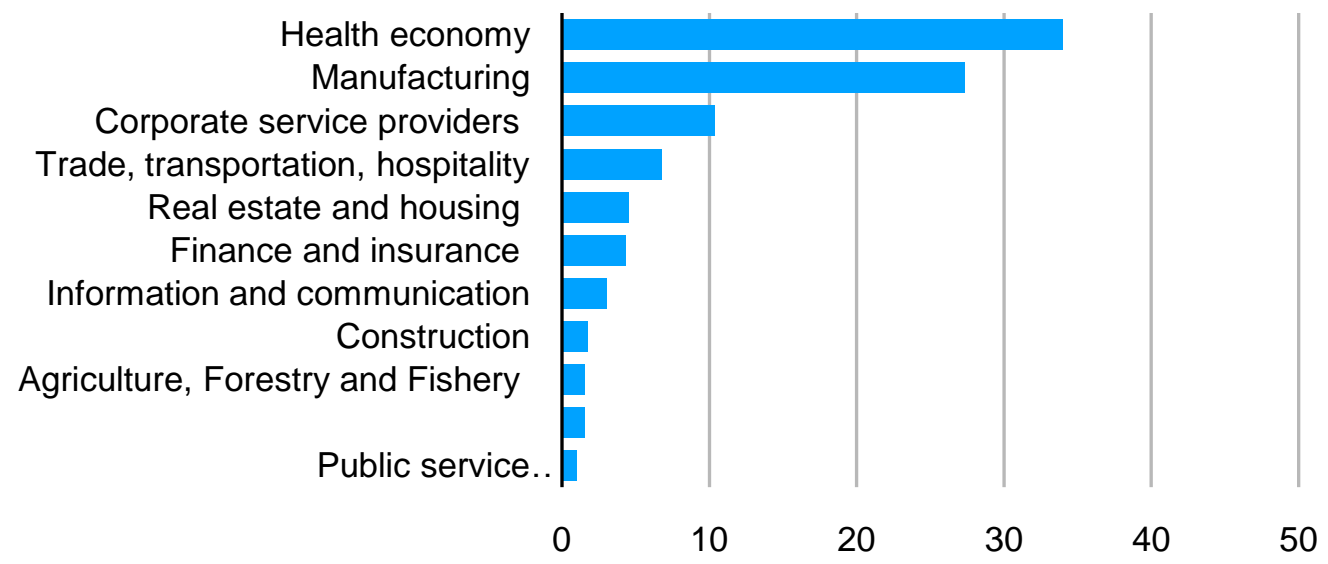

Source: Adapted from .Federal Ministry for Economic Affairs and Energy (BMWi) 2017a.

In 2015, the German health economy generated 324.3 bn $€$ GVA directly, 133.5 bn $€$ indirectly, and 133.5 bn $€$ induced. This translates into a multiplier of 0.41 for indirect, and 0.41 of induced GVA effects. Each $€$ GVA created within the health economy generated an additional $0.82 €$ within the overall economy in 2015 , amounting to a total of 591.3 bn € GVA in 2015(Schwärzler and Legler 2017).

In the same year, the health economy directly employed $6.8 \mathrm{~m}$ people and created approximately $2.1 \mathrm{~m}$ jobs indirectly and another $2.1 \mathrm{~m}$ jobs induced. This translates into a multiplier of 0.31 for indirect, and 0.31 for induced employment effects. Thus, each job within the health economy generated an additional 0.62 jobs in the overall economy. The health economy accounted for $11.0 \mathrm{~m}$ jobs in 2015(Schwärzler and Legler 2017)(Figure 5).

Figure 5Direct, indirect and induced GVA and employment effects of the German health economy, 2015

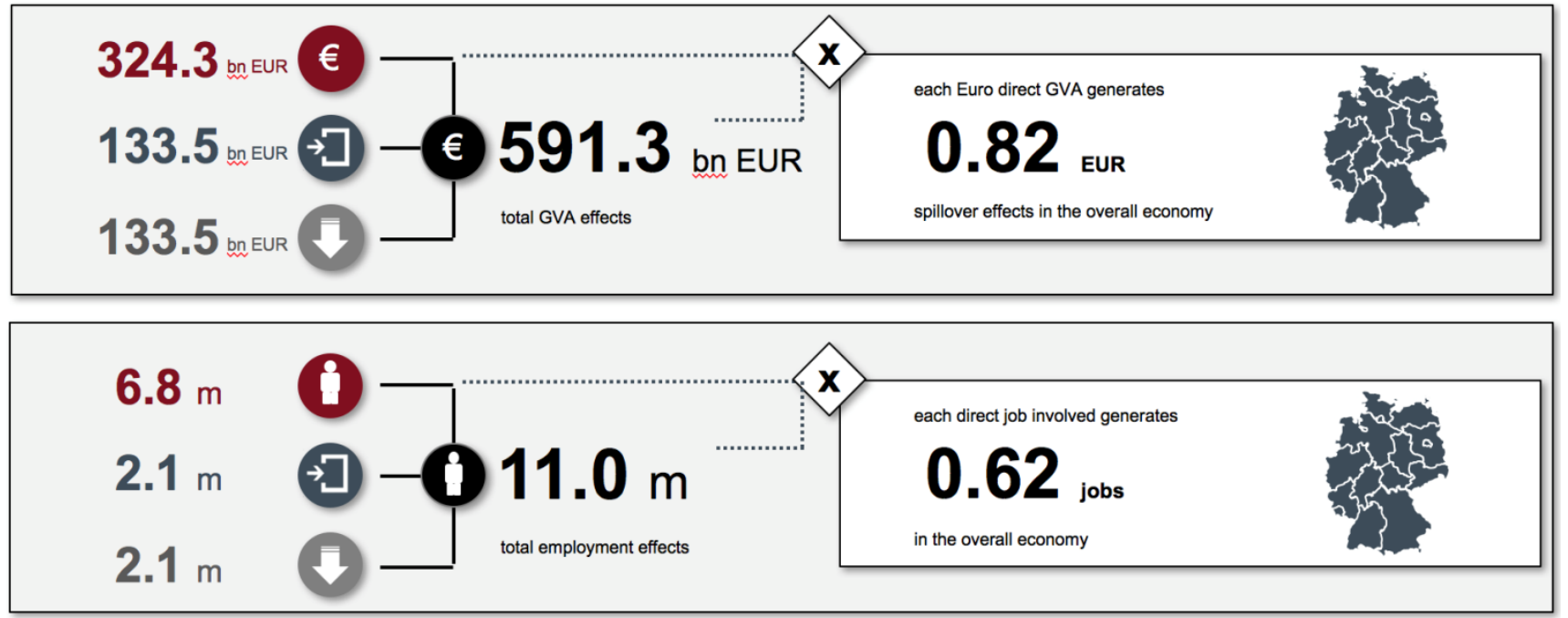

Source: Adapted from Schwärzler and Legler 2017.

\section{The role of the health economy within the total economy}

The health economy's importance to the overall German economy is demonstrated through its' $16.1 \%$ contribution to employment, $12.0 \%$ to GVA, and $8.2 \%$ to exports. Comparing and contrasting its' growth with that of the total economy over time allows more precise interpretation. Figure 6 shows the health economy's GVA growth rates have been positive since 2006, and growth has been increasing more rapidly since 2010. 
Compared to the overall economy, health economy GVA growth is less volatile, thereby stabilizing growth throughout the past decade(Federal Ministry for Economic Affairs and Energy (BMWi) 2017a).

Figure 6 GVA growth rates (\%) of the health and overall economy, 2006-2016

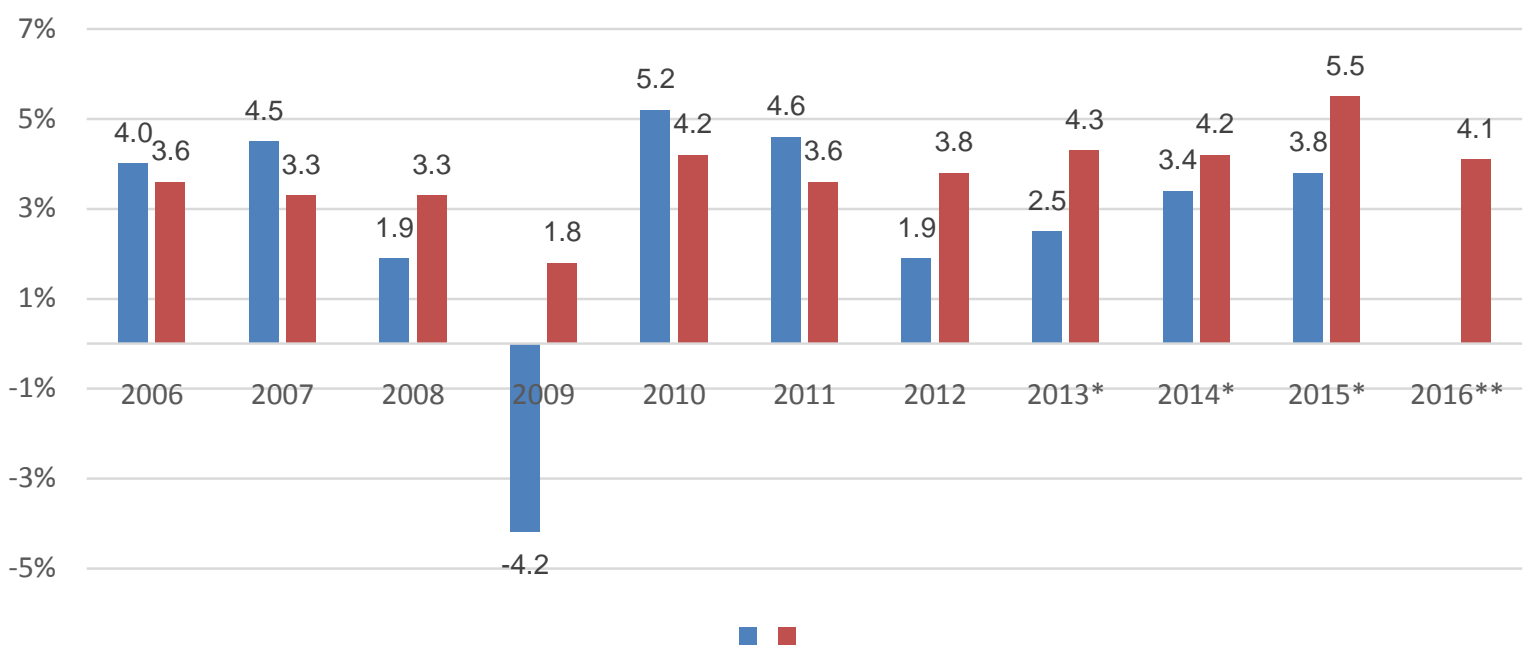

* extrapolation, ** prognosis. Note that data on GVA growth of the overall economy was not available following the release of the data base used.

Source: Adapted from Federal Ministry for Economic Affairs and Energy (BMWi) 2017a.

Over the past decade, the health economy grew nominally each year, including during the financial crisis in 2009, while its' GVA contribution to the overall economy rose steadily (Figure 7)(Federal Ministry for Economic Affairs and Energy (BMWi) 2017a).

Figure 7 Health economy GVA growth, total and as a proportion (\%) of the total economy

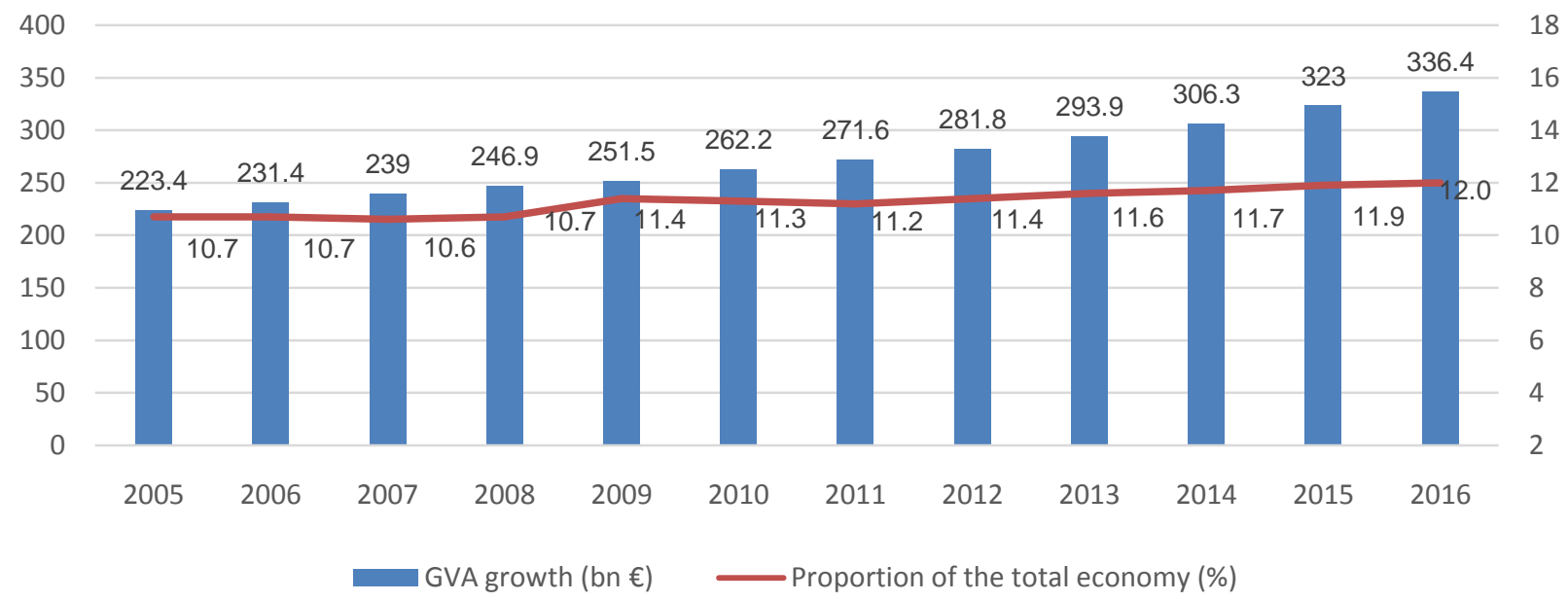

Source: Adapted from Federal Ministry for Economic Affairs and Energy (BMWi) 2017a.

\subsection{Sub-national reports}

The economic footprint and structure and importance of different health economy segments show considerable regional variation.For example, the health economy accounts for $13.6 \%$ of foreign trade in Brandenburg, but only $2.3 \%$ in Bremen (Figure 8)(Federal Ministry for Economic Affairs and Energy (BMWi) 2017a). 
Figure 2. Contribution of the health economy to foreign trade across Germany's 16 federal states, 2016

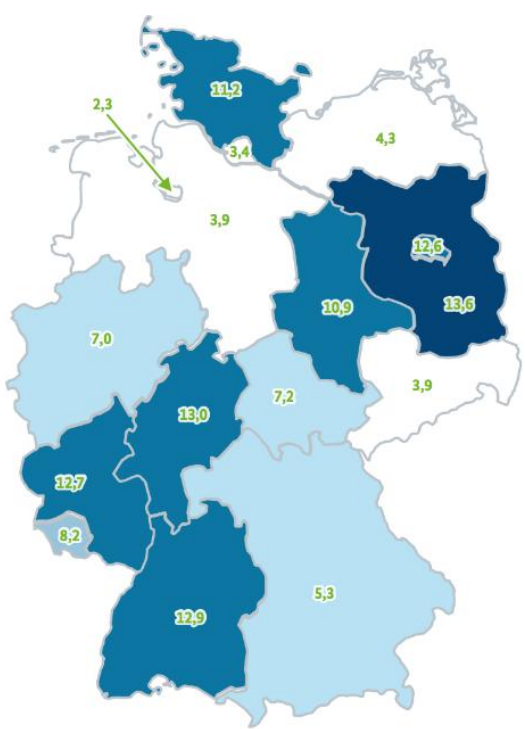

Source: Federal Ministry for Economic Affairs and Energy (BMWi) 2017a.

Sub-national health economy reports serve to compare regional economic footprints with each other and with the national health economy, to identify potential future growth opportunities and to monitor and adjust regional and national strategies in the context of competition and market regulations. The selected excerpts from Federal State health economy reports in this sub-chapter compare and contrast the structure and importance of different segments of the health economy. Table 2 presents basic health economy performance indicators for three selected Federal States(Ostwald, Legler, and Schwärzler 2014, 2015; Ostwald et al. 2015).

Table 2Key health economy indicators for selected regions of Germany

\begin{tabular}{|c|c|c|c|}
\hline & Gross value added & $\begin{array}{l}\text { Health economy } \\
\text { employment ( } \% \text { of total } \\
\text { employment) }\end{array}$ & $\begin{array}{l}\text { Foreign trade } \\
\text { (\% of total exports) }\end{array}$ \\
\hline Hamburg (2013) & 8.2 bn $€(9.4 \%)$ & $\begin{array}{l}162,000 \text { people directly } \\
\text { employed }(13.7 \%)\end{array}$ & $€ 2.7$ billion $(5.5 \%)$ \\
\hline $\begin{array}{l}\text { Mecklenburg-Western } \\
\text { Pomerania (2014) }\end{array}$ & 5.1 bn $€$ direct $(14.6 \%)$ & $\begin{array}{l}136,600 \text { people directly } \\
\text { employed }(18.7 \%)\end{array}$ & $97.2 \mathrm{~m} €(1.4 \%)$ \\
\hline Thuringia (2013) & 6.0 bn $€(13.1 \%)$ & $155,000(15.1 \%)$ & $900 \mathrm{~m} €(7.4 \%)$ \\
\hline
\end{tabular}

Source: Ostwald, Legler, and Schwärzler 2015; Ostwald et al. 2015; Ostwald, Legler, and Schwärzler 2014.

Hamburg's federal health economy report identified the following priorities. Firstly, with 2.7 bn $€$ - a $5.5 \%$ contribution to the region's exports, the industrial health economy provides important impulses for foreign trade, particularly in light of the region's export deficit. Secondly, with its' high density of hospitals and practitioners, Hamburg provides healthcare not only for its own, but also for the populations of Lower Saxony and SchleswigHolstein. Thirdly, the secondary health market, which generates approximately 2 bn $€$ GVA or a quarter of the total health economy, offers prospects for employment, as its' growth is $0.6 \%$ higher than in the primary health(Ostwald, Legler, and Schwärzler 2015).

In Mecklenburg-Western Pomerania and Thuringia, health tourism and organic food, which belong to the extended health economy and are predominantly financed through private consumption, play increasingly important roles. In Mecklenburg-Western Pomerania, health tourism contributes $4 \%$ of overall health economy GVA, which is double than its' national average. And each $€$ of GVA through the production of organic food contributes an additional $2.57 €$ in indirect and induced effects throughout the whole economy of the state(Ostwald et al. 2015). 
In Thuringia, health tourism contributes $2.4 \%$ of employment $(3,700)$. Overnight stays are growing more rapidly than in Germany as a whole on average, and more rapidly than for other forms of tourism in Thuringia ${ }^{6}$. And organic food experienced a $30 \%$ growth in GVA from $15.1 \mathrm{~m} €$ to around $55 \mathrm{~m} €$ from 2005-2013 (Ostwald, Legler, and Schwärzler 2014).

While these trends demonstrate the growing importance of the extended health economy and health-promoting products and services financed through private consumption, they need to be put into perspective with developments in the core health economy. In Mecklenburg-Western Pomerania, with an average $2.7 \%$ annual GVA growth, the medical technology segment contributes four times more than the overall health economy. In Thuringia, life sciences ${ }^{7}$ are an important driver of growth and employment. From 2005-2013, GVA within the production of medicines grew $10 \%$ more than national average, and employment $22 \%$ more respectively. GVA in research and development grew by $33.8 \%$, equaling more than double the average national increase, while employment grew by $36.6 \%$, outweighing the national average by $14.5 \%$ (Ostwald, Legler, and Schwärzler 2014; Ostwald et al. 2015).

\subsection{Thematic reports}

In addition to regional variations, the relative importance of different health economy segments is of interest to policy makers and other stakeholders. The following excerpts from thematic reports look at sub-segments based on particular interests within the German health economy reports.

\section{Medical products and technology}

With a $10.2 \%$ share of global medical products and technology production, Germany is the third biggest producer of medical technology worldwide. While the industrial health economy further comprises medication, body, mouth and dental care products, sports and fitness equipment, research and development, and wholesale trade, zooming into the medical products and technology sub-segment of the industrial health economy can inform policy making and investment decisions based on growth, employment and foreign trade objectives. Figure 9 shows the distribution of the medical products and technology sub-sector's share of total sales and enterprises across Germany's 16 Federal States (Federal Ministry for Economic Affairs and Energy (BMWi) 2017b).

Figure 3 Regional share of total sales (left) and total enterprises* (right) in the medical products and technology sub-sector, 2014
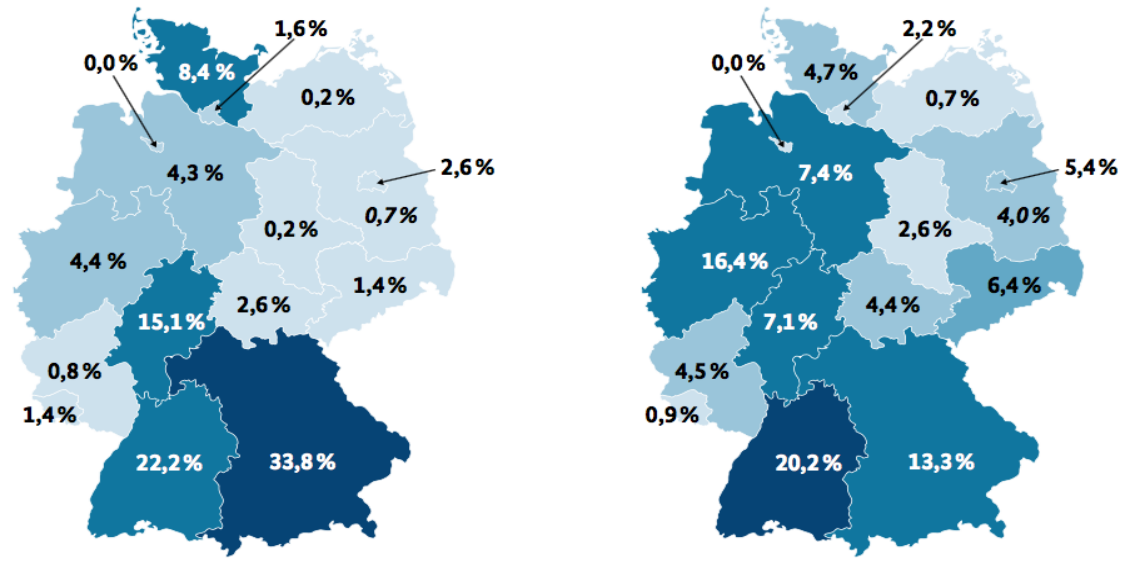

*Enterprises are defined as those employing more than 20 people.

Source: Federal Ministry for Economic Affairs and Energy (BMWi) 2017b.

In 2014, the medical products and technology segment had 188,500 direct employees, which constituted $2.7 \%$ of health economy employment and $20.3 \%$ of the industrial health economy. GVA through the production of medical products and technology amounted to $13.2 \mathrm{bn} €$, which constituted $3.9 \%$ of the total and $18.4 \%$ of the industrial health economy. With its annual exports amounting to $26.0 \mathrm{bn} €$ in 2016 , the segment contributed about $22.4 \%$ of total health economy exports.

\footnotetext{
${ }^{6}$ Health tourism incorporates the extended health segment categories E2 and E3. While hotel and accommodation services are extracted from E2, the E3 services offered by tour operators and public baths and spas add to the quantification of health tourism.

${ }^{7}$ According to the State Development Corporation of Thuringia, Life Science incorporates the medical technology, biotechnology and pharmaceutical industries. While these three branches are commonly summarized as the industrial health economy, the definition applied here incorporates economic activities of research and development institutions. Thus, life science compromises the core health segment categories $\mathrm{H} 1, \mathrm{H} 2$ and an aspect of the extended health segment category E3.
} 
While the sub-sector's exports had been growing on average $4.7 \%$ p.a. since 2005 , which is similar to that of the total economy at $4.8 \%$ p.a. its' growth was below that of the overall health economy ( $7.4 \%$ per annum)(Federal Ministry for Economic Affairs and Energy (BMWi) 2017b).Small and medium size enterprises ${ }^{8}$, growing in numbers in recent years, constituted $99.4 \%$ of enterprises within the sub-sector and produced over $75.8 \%$ of its GVA. In contrast, large enterprises ${ }^{9}$ made up only $0.6 \%$ of enterprises and had been decreasing in numbers recently, but still produced $24.2 \%$ of value added within the industrial health economy (Federal Ministry for Economic Affairs and Energy (BMWi) 2017b).

\section{Health economy workforce}

With continuous growth over the past decade (Figure 10) and $7 \mathrm{~m}$ people directly employed in 2016, the health economy contributes $16.1 \%$ of total employment in Germany and contributed $50 \%$ of total employment growth, or 620.000 out of $1.1 \mathrm{~m}$ new jobs, from 2000 to 2009(Federal Ministry for Economic Affairs and Energy (BMWi) 2017a).

Figure 10 Health economy employment in Germany, 2005-2016

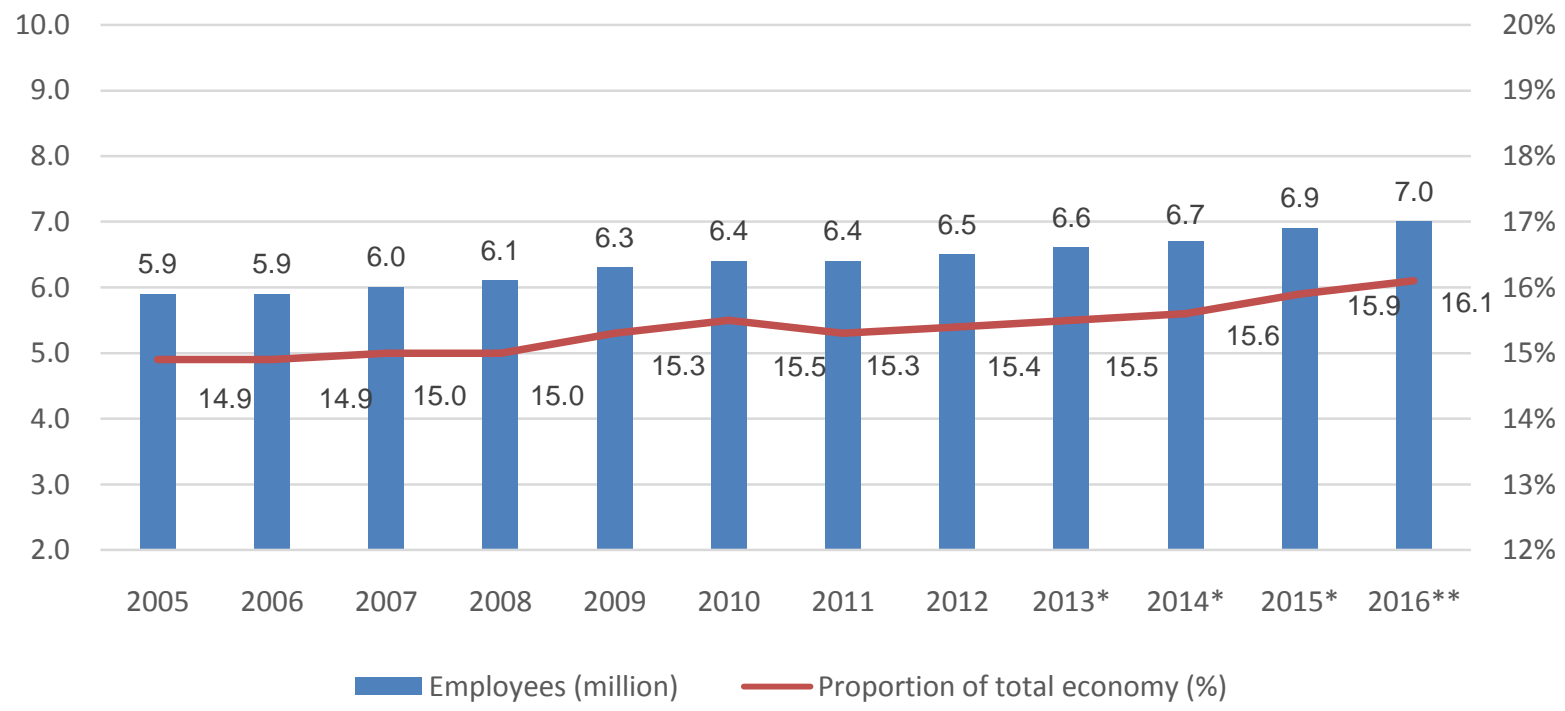

*extrapolation, **prognosis

Source: Adapted from Federal Ministry for Economic Affairs and Energy (BMWi) 2017a.

About $75 \%$ of health economy employment is attributed to the core health economy, largely in inpatient and outpatient institutions, such as doctors and physiotherapists, nursing care services and homes, hospitals, and rehabilitation clinics, while $25 \%$ of employment is attributed to the extended health economy. Employment growth is strong in labour intensive services segments, while the technology and capital intense upstream goods and services can substitute labour. From 2000-2009, more than two thirds of new jobs were generated in the outpatient segment, while employment in inpatient services increased exclusively in nursing, but decreased in hospitals. Simultaneously, employment growth in the production of medicine increased slightly, but full-time staff numbers declined. In medical technology, optical industry, medical laboratories and wholesale trading, employment grew by over $18 \%$, and staff numbers in research and development continued to rise(Federal Ministry for Economic Affairs and Energy (BMWi) 2017a).

Employment growth by healthcare professions ${ }^{10}$ is highest in medicine, sport and physical exercise, nursing care and outpatient therapy, while technology and ambulance services are behind. Wellness occupations have also seen rapid growth since the 2000's. These developments show innovation processes regarding the knowledge and skills of health personnel and health technology, while the demographic transition increases demand for management of noncommunicable diseases and multimorbidity. This in turn increases employment in occupations, such as wound treatment, technology assistance and medical controlling(Federal Ministry of Economics and Technology (BMWi) 2012).

\footnotetext{
${ }^{8}$ Small and medium size enterprises are defined as those employing less than 250 employees and generating less than $50 \mathrm{~m} €$ annual revenue.

${ }^{9}$ Large enterprises are defined as those generating more than $50 \mathrm{~m} €$ annual revenue

${ }^{10}$ The independent occupational area "health" can be divided into eight sub-categories: ambulance service, nutrition, medical and rehabilitation, nursing care, therapy (paramedical), medicine, psychology, and occupations related to sport and physical exercise.
} 
Over the past decade, the proportion of female doctors employed in hospitals grew from $38.1 \%$ in 2005 to $46.2 \%$ in 2015, at an average $4.9 \%$ growth p.a. compared to $1.5 \%$ growth p.a. for male doctors. As a growing employer of women, the health economy can play important roles in promoting gender equality(World Health Organization 2016).

\section{Applicability}

Health economy reporting allows for a whole range of detailed analyses of the economic impacts of health economies. Based on a product-specific segmentation, the health economy reporting methodology quantifies the following aspects:

- The direct gross value added, employment and foreign trade impacts of the health economy overallas well as for selected components and geographic areas depending on the areas of interest (basic health economy indicators)

- The indirect and induced gross value added, employment and foreign trade impacts, or spill-over effects, of the health economy on the overall economy, both for the health economy overall, as well as for selected components and geographic areas, depending on the areas of interest

- Interlinkages of different segments, as well as interlinkages of segments of the health economy with the overall economy, based on spillover effects

- The trends and developments of the health economy workforce; overall and disaggregated by the various segments of the health economy and

- The distribution of publicly and privately financed consumption within the health economy based on the financespecific segmentation.

Complementing the health economy reports with the social accounting matrix ${ }^{11}$ and integrating comprehensive social and health statistics enables countries to analyze (Schneider et al. 2015):

- The financing of the health economy, i.e. the impacts of the health economy on primary and secondary income distribution, and the impacts on the financing agencies, including government and social insurance

- The health dividend, i.e. the impact of the health economy and consumption of its products and services on health, based on selected health indicators, such as life expectancy or wellbeing; and

- The productivity of health economy; i.e. the relationship between input and outputs, measured as the change in the value of output per hour worked (Schneider et al. 2015).

\section{Outlook: Opportunities for application in other countries}

\subsection{Strategic opportunity}

Health economy reporting provides a structured approach for governments, private sector and general public stakeholders to better understand the size and impact of the health economy as a starting point for planning and evaluating its strategic role for health and sustainable and inclusive economic growth. The methodology of health economy reporting applies an economic policy perspective to health, in matching health expenditure surveys with national accounts to review the health economy as part of the overall national economy. Acknowledged by the HighLevel Commission on Health Employment and Economic Growth (World Health Organization 2016), health economy reporting is a very useful tool for advocacy and capacity building to enable evidence-based health policy that can steer and guide investments for health, employment and inclusive and sustainable growth. The following sub-chapters provide strategic entry points for future opportunities of engagement.

\subsection{Going beyond national health accounts}

The system of NHAs is used widely across countries to systematically track both the magnitude - i.e. the total amount of funding for health in the country, as well as the flow of that funding through the health sector. The existing methodology uses a comprehensive approach which looks at the total expenditures from all sources, including public, private and donor contributions, as well as across both current and capital expenditures, and across all disease areas. It describes expenditures for all health activities on an annual basis. As an internationally standardized methodology, the NHA allows countries to understand the source, magnitude, and flow of funds through their health sectors(World Health Organization, World Bank, and United States Agency for International Development 2003).

The methodology reviewed here is a distinct concept to that of the NHA, as it matches data from health expenditure surveys with data from national accounts to picture the health economy within the overall national economy and to surface its' contribution to growth and employment.

\footnotetext{
${ }^{11}$ The social accounting matrix extends the input-output systems of the health economy by including distribution and redistribution transactions. This integrated system ensures consistency of the different viewpoints on the health system, and their links to each other.
} 
While it builds on the methodology of the NHA, it goes beyond its' analytical capabilities to comprehensively inform health investment decisions about their employment and growth impacts.

\subsection{Requirements and entry points for implementation}

Conducting health economy reporting in other countries involves certain technical standards, capacity building and national ownership.

\section{Data availability}

\section{Stakeholder involvement}

Implementing the methodology and building national capacities to ensure sustainability can take both a national approach focusing on single countries, and a sub-regional approach focusing on existing sub-regional networks. At national level, Ministries of Economics and Ministries of Health take the lead in establishing a system of health economy reporting. In addition, national statistical offices, and relevant sub-national bodies and associations need to be involved.

At the regional level, sub-regional networks, could provide suitable platforms for advocacy, knowledge translation, capacity building and implementation of health economy reporting.

\section{Implementation process}

As illustrated in Figure 11, the process of implementing national health economy reporting should be accompanied by capacity building components to train national and/or regional key stakeholders to implement health economy reporting in full ownership. The implementation process outlined here is an example of a modular approach that can be adapted to the specific requirements in countries or sub-regions.

The inception workshop should first and foremost introduce the rationale, methodology, applicability and value added of introducing health economy reporting based on national accounts and generate interest among relevant stakeholders. The event should also feature an outlook on the requirements and steps to implement the methodology, and on the capacity building components, and identify key stakeholders' responsibilities to agree on a roadmap with key milestones and the establishment of national technical working groups with focal points.

Figure11 Implementation process for health economy reporting

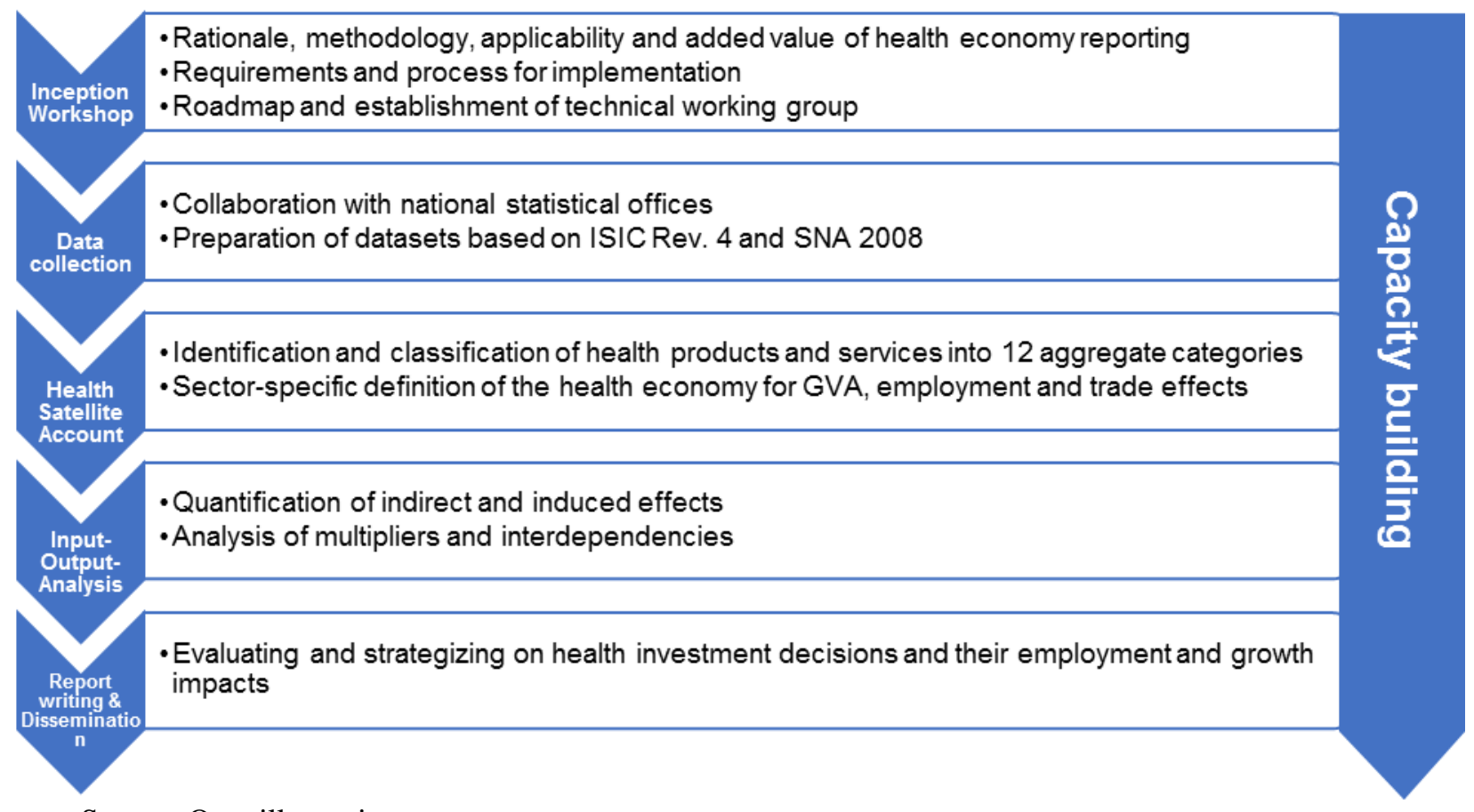

Source: Own illustration.

The collection and preparation of statistical data requires collaboration with national statistical offices to access and prepare the required datasets based on the statistical standards of ISIC Rev. 4and SNA 2008. The calculation of a health satellite account involves the identification and classification of health products and services within the overall economy into the twelve aggregate categories of the health economy. 
This quantification of the health economy is based on official data following the international standards SHA 2011 and ISIC Rev. 4 (United Nations Department of Economic and Social Affairs 2008). Based on supply and use information, the health economy is then defined from the sector-side to conclude on its relevance for GVA, employment and trade.

The input-output-analysis based on the health-specific supply and use tables then serves to quantify the indirect and induced effects of the health economy, and to analyse the multipliers and interdependencies of the health economy with the overall economy.

Finally, the process of report writing and dissemination puts the analysis and results into the perspective of (sub-) regional, national and sub-national health investment decisions and their employment and growth impacts. The reports serve to evaluate and strategize on health investment decisions should be disseminated among the stakeholders involved in the process.

The implementation process should be accompanied by capacity building measures, for example through hands-on working sessions and webinars.

\section{Conclusion}

Targeted investments in health play a key role as job generator and driver of inclusive and sustainable economic growth. Health economy reporting provides a structured approach for governments, private sector and general public stakeholders to better understand the size and impact of the health economy as a starting point for planning and evaluating its strategic role for health and sustainable and inclusive economic growth.

This analytic summary report reviewed a well-established methodology of health economy reporting that quantifies and analyses the health sector's economic impact on growth and employment based on national accounts. Beyond this, the report identified the strategic opportunity to use the method as a tool for advocacy and capacity building to enable evidence-based health policy to steer and guide investments for health, employment and inclusive and sustainable growth.

As such, the report serves as an entry point for countries who want to use expert services available for health economy reporting and related capacity building as a practical approach for implementing the 2030 Agenda for Sustainable Development.

Annex

Segmentation of products and services in the health economy based on the 4-quadrant-model

Core health area

H1 Medication

H11 Pharmaceutical products

H12 Chemical products

H2 Medical devices

H21 Medical technology products

H22 Wheelchairs

H23 Digital medical technology products

H3 Retail trade services of the core area

H31 Retail trade services for medication

H32 Retail trade services for medical devices

H4 Health insurance

H41 Social health insurance and public administration

H42 Private health insurance

H5 Services of inpatient facilities

H6 Services of non-inpatient facilities

H7 Wholesale trade services of the core area

H71 Wholesale trade services for medication

H72 Wholesale trade services for medical devices

H73 Commission trade services for the core area 
Extended health area

E1 Products for self-contained health care

E11 Products for personal hygiene, nutritional supplements

E12 Organic food

E13 Anti-allergenic clothing

E14 Literature for health and medical science

E15 Sports equipment

E2 Services for sports, wellness and tourism

E21 Services for sports

E22 Services for wellness and tourism

E3 Other services of the health economy

E31 Consultancy for healthcare facilities

E32 Other services of health care facilities

E33 Advocacy and information services of the health economy

E34 Trade services of the extended area

E4 Investment

E41 Education of health professionals

E42 Research and development of the health economy

E43 Advocacy and information services of the health economy

E44 Architectural services for the construction of healthcare facilities

E5 E-Health

E51 Appliances of telecommunication technology and data processing for the healthcare sector

E52 Services of information technology within the health care sector

E53 Services of data processing within the health care sector

The definition and segmentation of products and services within the health economy is based on official statistical standards for national accounts and the system of health accounts. This enables accounting for health-related products and respective producing entities within the overall economy while maintaining balancing conditions and concepts of national accounts.

Source: (Schwärzler and Kronenberg 2016)

\section{Bibliography}

European Commission, International Monetary Fund, Organisation for Economic Co-operation and Development, United Nations, and World Bank. 2009. System of National Accounts 2008. New York. https://unstats.un.org/unsd/nationalaccount/docs/SNA2008.pdf.

Federal Ministry for Economic Affairs and Energy (BMWi). 2015. 'National Health Account for Germany. Summary of the Research Project of the Federal Ministry for Economic Affairs and Energy'. Berlin. https://www.wifor.com/tl_files/wifor/publikationen/2015_Bericht_BMWi_GGRII_Zusammenfassung_ENGLI SCH.pdf. 2017a. 'Gesundheitswirtschaft. Fakten \& Zahlen. Ausgabe 2016'. Berlin.

. 2017b. 'Gesundheitswirtschaft. Fakten \& Zahlen, Ausgabe 2016, Sonderthema Medizinprodukte Und Medizintechnik'. Berlin.

Federal Ministry of Economics and Technology (BMWi). 2012. 'Stimuli to Innovation in the Healthcare Industry. Effects on Healthcare Costs, Competitiveness and Employment Results of the Research Project of the Same Name Carried out on Behalf of the Federal Ministry of Economics and Technology (BMWi)'. Berlin.

Hamelmann, Christoph, Federica Turatto, Volker Then, and Mariana Dyakova. 2017. 'Social Return on Investment: Accounting for Value in the Context of Health 2020 and 2030 Agenda for Sustainable Development Implementation'. Copenhagen: World Health Organization Regional Office for Europe. 
Henke, Klaus-Dirk, Karsten Neumann, Markus Schneider, Anja Georgi, Jan Bungenstock, Michael Baur, Sabine Ottmann, Thomas Krauss, and Uwe Hofmann. 2010. Erstellung eines Satellitenkontos für die Gesundheitswirtschaft in Deutschland. 1st ed. Europäische Schriften zu Staat und Wirtschaft 30. Baden-Baden: Nomos.

Henke, Klaus-Dirk, and Dennis A. Ostwald. 2012. 'Health Satellite Account: The First Step'. International Journal of Behavioural and Healthcare Research 3 (2): 91-105.

Organisation for Economic Co-operation and Development, World Health Organization, and Statistical Office of the European Communities, eds. 2011. A System of Health Accounts 2011. Paris.

Ostwald, Dennis A., Benno Legler, and Marion C. Schwärzler. 2014. 'Ökonomischer Fußabdruck Der Gesundheitswirtschaft in Thüringen Unter Besonderer Berücksichtigung Der Industriellen Gesundheitswirtschaft'. Darmstadt/Erfurt: WifOR, Landesentwicklungsgesellschaft Thüringen mbH (LEG).

Ostwald, Dennis A., Benno Legler, and Marion Cornelia Schwärzler. 2015. 'Untersuchung Der Ökonomischen Bedeutung Der Gesundheitswirtschaft in Hamburg'. Darmstadt, Hamburg: Gesundheitswirtschaft Hamburg $\mathrm{GmbH}$.

Ostwald, Dennis A., Benno Legler, Marion Cornelia Schwärzler, and Simon Tetzner. 2015. Der Ökonomische Fußabdruck Der Gesundheitswirtschaft in Mecklenburg-Vorpommern. Analyse Der Volkswirtschaftlichen Bedeutung Für Wirtschaftswachstum, Arbeitsmarkt Und Außenhandel Unter Besonderer Berücksichtigung Des Mittelstandes. Darmstadt: BioCon Valley GmbH.

Schneider, Markus, Dennis A. Ostwald, Alexander Karmann, Klaus-Dirk Henke, and Grit Braeseke. 2015. 'Gesundheitswirtschaftliche Gesamtrechnung 2000 - 2014. Überprüfung Der Methodik Und Notwendige Anpassungen, Insbesondere an Die Wirtschaftszweigklassifikation 2008'. Berlin: Nomos.

Schwärzler, Marion Cornelia, and Tobias Kronenberg. 2016. 'Methodology of the National Health Account for Germany - Database, Compilation and Results'. MPRA Paper 73561. Munich: Munich Personal RePEc Archive. https://mpra.ub.uni-muenchen.de/73561/.

Schwärzler, Marion Cornelia, and Benno Legler. 2017. 'Der Ökonomische Fußabdruck Der Gesundheitswirtschaft in Deutschland Nach ESVG 2010. Analyse Der Volkswirtschaftlichen Bedeutung Für Wirtschaftswachstum, Arbeitsmarkt Und Außenhandel 2000 Bis 2015'. MPRA Paper 79066. Munich: Munich Personal RePEc Archive. https://mpra.ub.uni-muenchen.de/79066/.

United Nations Department of Economic and Social Affairs. 2008. International Standard Industrial Classification of All Economic Activities (ISIC), Rev. 4. New York: United Nations.

United Nations General Assembly. 2015. 'Transforming Our World: The 2030 Agenda for Sustainable Development. A/RES/70/1'. New York: United Nations.

United Nations High Level Political Forum on Sustainable Development. 2017. 'HLPF Thematic Review of SDG 3: Ensure Healthy Lives and Promote Well-Being for All at All Ages'. New York: United Nations. https://sustainabledevelopment.un.org/content/documents/14367SDG3format-rev_MD_OD.pdf.

United Nations Informal Interagency Task Team on Sustainable Procurement in the Health Sector (SPHS). n.d. 'Saving Lives Sustainably'. Accessed 31 July 2017. http://savinglivesustainably.org.

World Health Organization. 2013. 'Health 2020. A European Policy Framework and Strategy for the 21st Century'. Copenhagen: World Health Organization.

2015. 'Landscape Analysis for the Technical Consultation, Bonn 29-30 August 2013'. UN Initiative on Greening Procurement in the Health Sector: From Products to Services. Bonn: World Health Organization.

2016. 'Working for Health and Growth. Investing in the Health Workforce. Report of the High-Level Commission on Health Employment and Economic Growth'. Geneva: World Health Organization.

World Health Organization, World Bank, and United States Agency for International Development. 2003. 'Guide to Producing National Health Accounts with Special Applications for Low-Income and Middle-Income Countries'. Geneva: World Health Organization. 